\title{
Bridge Deterioration Prediction Model Based On Hybrid Markov-System Dynamic
}

\author{
Jojok Widodo Soetjipto ${ }^{1,2,}{ }^{*}$, Tri Joko Wahyu Adi $^{1}$, and Nadjadji Anwar ${ }^{1}$ \\ ${ }^{1}$ Department of Civil Engineering, Institut Teknologi Sepuluh Nopember, 60111 Surabaya, Indonesia \\ ${ }^{2}$ Department of Civil Engineering, The University of Jember, 68111 Jember, Indonesia
}

\begin{abstract}
Instantaneous bridge failure tends to increase in Indonesia. To mitigate this condition, Indonesia's Bridge Management System (I-BMS) has been applied to continuously monitor the condition of bridges. However, I-BMS only implements visual inspection for maintenance priority of the bridge structure component instead of bridge structure system. This paper proposes a new bridge failure prediction model based on hybrid Markov-System Dynamic (MSD). System dynamic is used to represent the correlation among bridge structure components while Markov chain is used to calculate temporal probability of the bridge failure. Around 235 data of bridges in Indonesia were collected from Directorate of Bridge the Ministry of Public Works and Housing for calculating transition probability of the model. To validate the model, a medium span concrete bridge was used as a case study. The result shows that the proposed model can accurately predict the bridge condition. Besides predicting the probability of the bridge failure, this model can also be used as an early warning system for bridge monitoring activity.
\end{abstract}

\section{Introduction}

Indonesia has 89,000 bridges with a total length of $1,050 \mathrm{~km}$ connecting city/regency, provincial, and national roads [1]. The number of bridges will predictably increase as they are still needed to connect separated areas. Most areas in Indonesia are separated by rivers, valleys, seas, etc. As the areas mutually need each other, bridges are needed to connect them.

According to the 2012 Statistical Information Book of the Ministry of Public Works, $32.49 \%$ of bridges on the national roads were damaged and $1.5 \%$ collapsed [1]. The causes of the damages and collapses include overloading, foundation damage, structural damage, bridge floor damage, etc.

Many studies have been conducted to early detect bridge damage or failure. FMEA (failure modes and effect analysis) is used to identify risks on scouring protector design of the pier and the abutment, and to determine a risk priority number in calculating risks and potentials as well as the mitigating scenarios [2]. FTA (Fault Tree Analysis) is also often employed to determine the causative factors and incident estimations of bridge failure [3].

* Corresponding author: jojok.teknik@unej.ac.id 
SHM is a brige damage prediction method which is currently developing. The method is commonly employed for monitoring bridge structural behavior due to natural disasters, temperature, bridge loading, etc [4].

Such studies still have some drawbacks, which include the bridge elements and components assumed to have independent behavior. Yet, the behavior and damage of bridges are complex, influenced by the relationships between bridge elements and components. The damage of one element might influence other elements and the other way around. Therefore, research on the behavioral relationships between bridge elements/components to detect elements/components predominantly affecting the condition of a bridge is needed. In this research, joint probability method was used for identifying the most dominant relationship between bridge components. On the other hand, Markov Chain was used for predicting the probability of bridge condition [5]. The two methods were integrated with System Dynamic (SD). SD is a tool which has the ability to create a simulation in a complex system. Furthermore, system dynamic has often been used to analyze bridge damage and its monitoring [6].

\section{Model Constructions}

For developing a model, sufficient data and proposed model are required. Such data are used for making and validating the model. Meanwhile, the proposed model should be able to solve the calculation analysis more easily and applicable for further analysis, for example optimation, sensitivity, simulation, etc.

\subsection{Data Collections}

In Indonesia, Manual Book for Bridge Inspection published by Directorate General of Bina Marga, the Ministry of Public Works, is used as the main reference for bridge monitoring. The book is used for Bridge Management System (BMS) aimed at assessing and evaluating bridge condition. The bridge structure is classified into five levels: bridge, upper and sub structure of bridge, foundation and pier, pile and bridge wall, and small elements individually. The element assessment system consists of five factors: structure, damage, volume, function, and influence. Meanwhile, the value given is 1 if there is a damage, and 0 if there is no damage or the damage has not taken place. The condition value of bridge components is between 0 (no damage on the bridge) and 5 (bridge cannot be used) [7].

In this research, data were obtained from 235 bridges which have the same construction, that is reinforced-concrete girder bridge. The data were obtained from Directorate of Bridge, Directorate General of Bina Marga, the Ministry of Public Works and Housing. The data were from visual inspections based on BMS in East Java from 2010 to 2016. For modelling, data from 2010 to 2014 were used as a model, while data from 2015 to 2016 were used for calibration/testing.

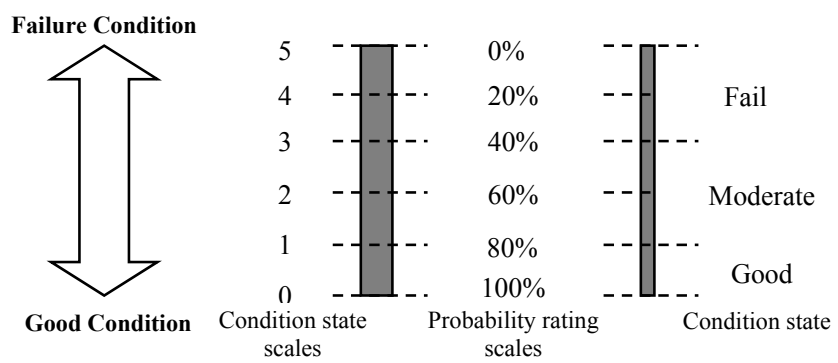

Fig. 1. Detail of condition state scales - probability rating and state 
The condition value of BMS can be employed for predicting the long-term condition of bridge elements [8]. The employed method used integrates the Markov Chain method (if the data are available) and BPM (Backward Prediction Model) as generating missing years' condition data with regression [9]. For the analysis, the condition value (0-5) on BMS was changed into probability rating and condition categories (Good $(\mathrm{G})$, Moderate $(\mathrm{M})$, and Fail (F)) on components and bridge (see Fig. 1).

Bridge condition is influenced by the condition of bridge components (abutment/pier, beam/girder and deck) and the relationships between such components. Bridge construction can collapse due to construction materials, such as fatique and deterioration. For predicting the deterioration of concrete, ANN (Artificial Neural Network) model can be employed [10], while FRM (Fatique reliability model) can be used for predicting fatique [11]. The relationships between components can also cause bridge construction collapse. This is shown by data of bridges which collapsed due to abutment/pier conditions although the beam and deck bridge were in a good condition, vice versa. Therefore, research on the relationship behavior of the components is needed.

BMS data recording was applied to every element or bridge component, and the relationship pattern between the elements was not known. To identify the pattern of relationship between the component and bridge statistically, categorical data analysis was used. The analysis was able to evaluate whether the data were independent or dependent. Meanwhile, joint probability theory can be used to determine the strongest relationship probability between variables in a particular event. A more thorough analysis can be learned from the reference [12].

Generally, categorical data and joint probability analyses used chi-square test with the following steps: (i) making the matrix of relationship between variables (equation 1); (ii) making the matrix of probability variable (equation 2); (iii) making estimated-expected frequencies matrix (equation 3 and 4); (iv) calculating the varian value (equation 5); (v) conducting statistical test using chi-square.

$$
\begin{gathered}
\theta_{i j}=\text { Observation on category row } \mathrm{i} \text { dan column } \mathrm{j} \\
p_{i j}=\frac{\theta_{i j}}{n} \\
E_{i j}=n p_{i^{*}} p^{*} j=\frac{n_{i} m_{j}}{n} \\
p_{i^{*}}=\frac{n_{i}}{n} \quad \text { and } p^{* j}=\frac{m_{j}}{n} ; i=1,2,3, \ldots, 12 \text { and } j=1,2,3, \ldots, 12 \\
W=\sum_{\substack{i=1 \\
j=1}}^{12} \frac{\left(\theta_{i j}-E_{i j}\right)^{2}}{E_{i j}}
\end{gathered}
$$

From BMS data (Table 1) and calculation (equation (1)-(5)), a critical value of $\mathrm{W}=$ $11,256.14$ was obtained. Meanwhile, according to chi-square, the distribution table for $\chi_{(121 ; 0.05)}^{2}=140.17$. Thus, it can be concluded that the condition of the bridge and its components (Br: bridge, A: abutment, B: beam and D: deck) are dependent.

The probability of an event given one or more events can employ the conditional probability. The conditional probability can be calculated using bayes theorem. Calculating the probability of bridge condition given the condition of bridge components can be done using equation (6) and (7). The conditional probability of bridge given all of bridge components can be seen in Table 2. The most dominant bridge conditional probability occured if all bridge components are in good condition.

$$
P(Y \mid X)=\frac{P(Y, X)}{P(X)}
$$




$$
P\left(Y_{1}, Y_{2}, Y_{3}, \ldots Y_{n}\right)=P\left(Y_{1}\right) P\left(Y_{2} \mid Y_{1}\right) P\left(Y_{3} \mid Y_{1}, Y_{2}\right) \ldots P\left(Y_{n} \mid Y_{1}, Y_{2}, \ldots Y_{n-1}\right)
$$

Table 1. Probability condition of components of bridge based on BMS data

\begin{tabular}{|c|c|c|c|c|c|c|c|c|c|c|c|c|c|c|}
\hline & \multicolumn{3}{|c|}{ Bridge (Br) } & \multicolumn{3}{|c|}{ Abutment (A) } & \multicolumn{3}{|c|}{ Beam (B) } & \multicolumn{3}{|c|}{ Deck (D) } & \multirow{2}{*}{$\frac{\text { Prob. row }}{\mathrm{p}_{\mathrm{i}^{*}}}$} \\
\hline & & G & M & $\mathrm{F}$ & G & M & $\mathrm{F}$ & G & M & $\mathrm{F}$ & $\mathrm{G}$ & M & $\mathrm{F}$ & \\
\hline \multirow{3}{*}{$\mathrm{Br}$} & G & 0.0899 & 0.0000 & 0.0000 & 0.0899 & 0.0000 & 0.0000 & 0.0899 & 0.0000 & 0.0000 & 0.0331 & 0.0568 & 0.0000 & 0.2697 \\
\hline & M & 0.0000 & 0.0203 & 0.0000 & 0.0047 & 0.0156 & 0.0000 & 0.0142 & 0.0061 & 0.0000 & 0.0091 & 0.0109 & 0.0003 & 0.0610 \\
\hline & $\mathrm{F}$ & 0.0000 & 0.0000 & 0.0009 & 0.0001 & 0.0001 & 0.0007 & 0.0002 & 0.0004 & 0.0003 & 0.0001 & 0.0005 & 0.0003 & 0.0026 \\
\hline \multirow{3}{*}{ A } & G & 0.0899 & 0.0047 & 0.0001 & 0.0948 & 0.0000 & 0.0000 & 0.0920 & 0.0026 & 0.0001 & 0.0349 & 0.0596 & 0.0003 & 0.2843 \\
\hline & M & 0.0000 & 0.0156 & 0.0001 & 0.0000 & 0.0157 & 0.0000 & 0.0121 & 0.0036 & 0.0000 & 0.0074 & 0.0082 & 0.0001 & 0.0470 \\
\hline & $\mathrm{F}$ & 0.0000 & 0.0000 & 0.0007 & 0.0000 & 0.0000 & 0.0007 & 0.0002 & 0.0003 & 0.0001 & 0.0000 & 0.0004 & 0.0003 & 0.0020 \\
\hline \multirow{3}{*}{ B } & G & 0.0899 & 0.0142 & 0.0002 & 0.0920 & 0.0121 & 0.0002 & 0.1043 & 0.0000 & 0.0000 & 0.0399 & 0.0640 & 0.0004 & 0.3129 \\
\hline & M & 0.0000 & 0.0061 & 0.0004 & 0.0026 & 0.0036 & 0.0003 & 0.0000 & 0.0066 & 0.0000 & 0.0023 & 0.0041 & 0.0001 & 0.0197 \\
\hline & $\mathrm{F}$ & 0.0000 & 0.0000 & 0.0003 & 0.0001 & 0.0000 & 0.0001 & 0.0000 & 0.0000 & 0.0003 & 0.0000 & 0.0002 & 0.0001 & 0.0008 \\
\hline \multirow{3}{*}{ D } & G & 0.0331 & 0.0091 & 0.0001 & 0.0349 & 0.0074 & 0.0000 & 0.0399 & 0.0023 & 0.0000 & 0.0422 & 0.0000 & 0.0000 & 0.1266 \\
\hline & M & 0.0568 & 0.0109 & 0.0005 & 0.0596 & 0.0082 & 0.0004 & 0.0640 & 0.0041 & 0.0002 & 0.0000 & 0.0683 & 0.0000 & 0.2049 \\
\hline & $\mathrm{F}$ & 0.0000 & 0.0003 & 0.0003 & 0.0003 & 0.0001 & 0.0003 & 0.0004 & 0.0001 & 0.0001 & 0.0000 & 0.0000 & 0.0006 & 0.0018 \\
\hline $\begin{array}{l}\text { Prob. } \\
\text { Colum }\end{array}$ & $\mathrm{p}_{* \mathrm{j}}$ & 0.2697 & 0.0610 & 0.0026 & 0.2843 & 0.0470 & 0.0020 & 0.3129 & 0.0197 & 0.0008 & 0.1266 & 0.2049 & 0.0018 & 1.0000 \\
\hline
\end{tabular}

Table 2. Conditional probability of bridge

\begin{tabular}{|l|c|l|l|c|}
\hline No & \multicolumn{2}{|c|}{$\begin{array}{c}\text { Conditional } \\
\text { Probability }\end{array}$} & Condition component & Probability \\
\hline 1 & $\mathrm{P}(\mathrm{Br}$ & A,B,D $)$ & Biggest probability & 0.0853 \\
\hline 2 & $\mathrm{P}(\mathrm{Br}$ & $\mathrm{A}, \mathrm{B}, \mathrm{D})$ & Good & 0.0853 \\
\hline 3 & $\mathrm{P}(\mathrm{Br}$ & $\mathrm{A}, \mathrm{B}, \mathrm{D})$ & Moderate & 0.0348 \\
\hline 4 & $\mathrm{P}(\mathrm{Br}$ & $\mathrm{A}, \mathrm{B}, \mathrm{D})$ & Fail & 0.0012 \\
\hline
\end{tabular}

Dominant conditional probability between the components toward the bridge and between the bridge components can be determined by making joint probability between 2 variables. Thus, matrix in Table 1 was rearranged by reducing the variables, from 4 variables to 2 variables. The most dominant conditional probability value on the bridge and bridge components can be calculated using equation (6) and (7). The most dominant conditional probability can be seen in Table 3 .

Table 3. Order of bridge and its' component relationship.

\begin{tabular}{|c|c|c|c|}
\hline No & Conditional & Probability & Probability \\
\hline 1 & $\mathrm{P}(\mathrm{Br}=\mathrm{G}$ & $\mathrm{A}=\mathrm{G})$ & 0.2023 \\
\hline 2 & $\mathrm{P}(\mathrm{Br}=\mathrm{G}$ & $\mathrm{B}=\mathrm{G})$ & 0.2023 \\
\hline 3 & $\mathrm{P}(\mathrm{Br}=\mathrm{G}$ & $\mathrm{D}=\mathrm{M}$ & 0.1278 \\
\hline 4 & $\mathrm{P}(\mathrm{A}=\mathrm{G}$ & $\mathrm{B}=\mathrm{G})$ & 0.2070 \\
\hline 5 & $\mathrm{P}(\mathrm{B}=\mathrm{G}$ & $\mathrm{D}=\mathrm{M})$ & 0.1439 \\
\hline 6 & $\mathrm{P}(\mathrm{A}=\mathrm{G}$ & $\mathrm{D}=\mathrm{M})$ & 0.1342 \\
\hline
\end{tabular}

As seen in Table 3, the strongest interrelationship between the bridge and components occurred on abument and beam (each 0.2023 ), while the deck had a smaller relationship, that is 0.1278 . The relationship between components having the strongest interrelationship occured on the abument/pier with bean/girder, that is 0.2070 . The relationship between beam/girder with deck is 0.1439 , while the relationship between abument/pier with deck has the smallest value, that is 0.1342 . 


\subsection{Markov-System Dynamic (MSD) Modelling}

This study used Markov model for predicting bridge condition based on the current condition randomly [13]. This theory can be applied to predict future damages of bridges based on current conditions. The process of Xt can be said to have the Markov property if it fulfills equation (8). Markov is widely used because it can be applied to almost all fields of research. However, this model has some drawback; it requires repeated and longer calculation; it is more difficult to understand because it does not produce graphics automatically; furthermore, repeated calculations are also needed to determine steady conditions. Besides that, modelling is also required to generate an easier calculation method which can be applied to further calculations, such as optimation, simulation, sensitivity analysis, etc. Therefore, this research employs hybrid markov-system dynamic (MSD).

$$
P\left(X_{t-1}=j \mid X_{t}=i\right)=P\left(X_{I}=j \mid X_{0}=i\right) ; \text { for } t=0,1,2, \ldots, n .
$$

To build Markov-System Dynamic Model have several steps which are:

\section{Step 1: Constructing Conditional Probability Table (CPT)}

Data from the observation of bridge and the components are defined into 3 states: Good (G), Moderate (M), and Fail (F) (see Fig.1). The observation data used for making the model are data from 2010 to 2014, turned into CPT matrix using equation (9). Meanwhile, for calibrating the model, observation data from 2015 to 2016 are used.

$$
P_{i j}^{(v)}=\left[\begin{array}{cccc}
P_{00} & P_{o 1} & \cdots & P_{0 j} \\
P_{10} & P_{11} & \cdots & P_{1 j} \\
\vdots & \vdots & \vdots & \vdots \\
P_{i 0} & P_{i 1} & \cdots & P_{i j}
\end{array}\right]
$$

\section{Step 2: Building the MSD model}

For building the MSD model, causa-loop diagram (see Fig. 2a) and stock-flow diagram (see Fig 2b) are needed based on the behavior of Markov System (see Fig 2).

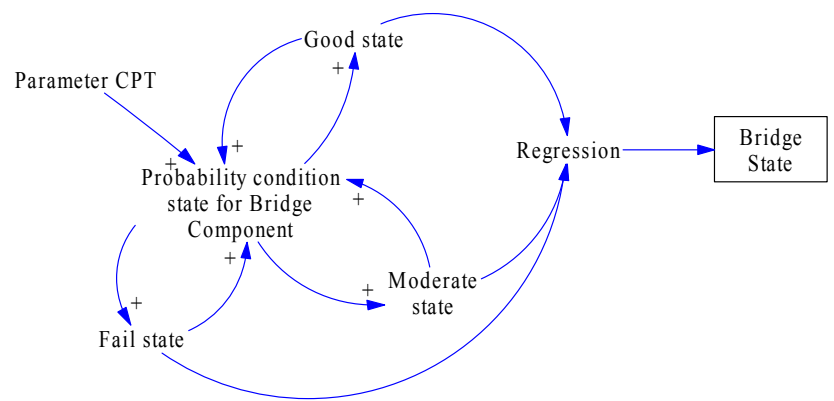

(a) Feedback-loop diagram

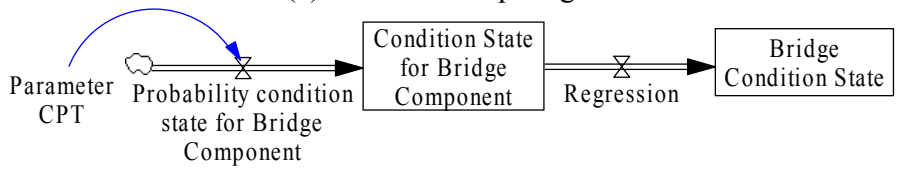

(b) Stock-flow diagram

Fig. 2. The MSD diagram concept

The basic concept of MSD model can be constructed based on Fig 2. CPT is a parameter for transition "probability condition state of bridge component" which has 3 states: G, M, and F. CPT becomes an input for stock on "condition state for bridge component" which 
also has 3 states: G (Good), M (Medium), and F (Fail). For predicting the bridge condition value based on the bridge component condition (abutment/pier, beam/girder, and deck), an approach using multiple linear regression equation is needed. Due to the limited features of Vensim PLE version, the multiple linear regression was done manually using matrix method (see step $7^{\text {th }}$ in the following MSD simulation)

\section{Step 3: MSD simulation}

After the MSD model has been constructed, the next step was making the simulation of the MSD model by using CPT at step 1 . The simulation used system dynamic software for running the model. The following is the alogarithm used:

Step1: calculating CPT by using equation (8) and (9) with a time limit of $T$ in the system determined 100 years

Step 2: Initially set $P G(t)=1$ and $P M(t)=P F(t)=0$

Step 3: A conditional loop was formed if $t<T$

Step 4: From one process to the next one, $t$ will increase as much as $d t$ where $t=t_{0}+d t$.

Step 5: Condition state was calculated based on the following equations:

$P G(t)=P G(t-d t)+C P T^{*} d t$

$P M(t)=P M(t-d t)+C P T^{*} d t$

$P F(t)=P F(t-d t)+C P T^{*} d t$

Step 6: The output of MSD on "Condition State for Bridge Component" can be presented in the forms of numbers and graphics

Step 7: The Multiple Linear Regression was calculated using matrix method with equations (13)-(18). Data $Y$ is the output MSD bridge condition, while $X_{1 i}, X_{2 i}, X_{3 i}$ is the output MSD bridge component with $i=1$ until steady state on output MSD.

$Y=\beta_{0}+\beta_{1} X_{1 i}+\beta_{2} X_{2 i}+\beta_{3} X_{3 i}+\ldots+\beta_{p} X_{p i}+\varepsilon_{i} ; i=1,2,3, \ldots, n$

$[Y]=\beta[X]+e$

$\beta=\left[X^{\prime} X\right]-1\left[X^{\prime} Y\right]$

$R^{2}=1-\frac{\sum_{e i}}{\sum_{y i}{ }^{2}}$

$\sum e i^{2}=e^{\prime} e$

$\sum y i^{2}=Y^{\prime} Y$

This regression equation can be used as an equation on flow "regression".

Step 8: Output of MSD and regression prediction "Bridge condition state" can be presented in the forms of numbers and graphics.

\section{Step 4: MSD scenario}

For observing the bridge condition behavior, a scenario by changing the CPT behavior of bridge component can be employed.

\section{Results and Discussions}

MSD model was used to predict the bridge condition and its components in 3 states: probability of Good, Moderate and Fail. The MSD simulation result can be seen in Fig 3. The bridge probability for good, moderate and fail are $0.84,0.14$ and 0.02 respectively. On average, the steady condition was achieved on year $26^{\text {th }}$. Based on each component of bridge: (i) the probability of good condition of abutment, beam and deck is $0.78,0.73$ and 0.82 respectively; (ii) the probability of moderate of abutment, beam and deck is $0.21,0.24$, 0.17 respectively; and (iii) the probability of fail condition of abutment, beam and deck is $0.01,0.03,0.01$ respectively. 


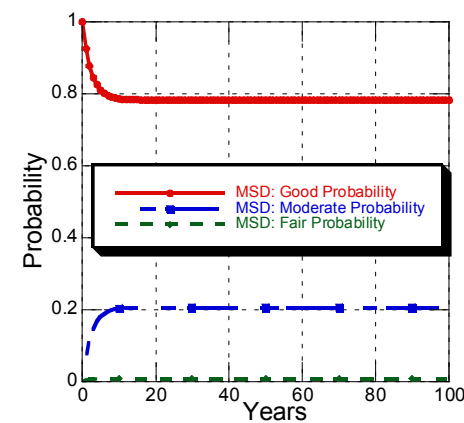

(a) MSD Abutment

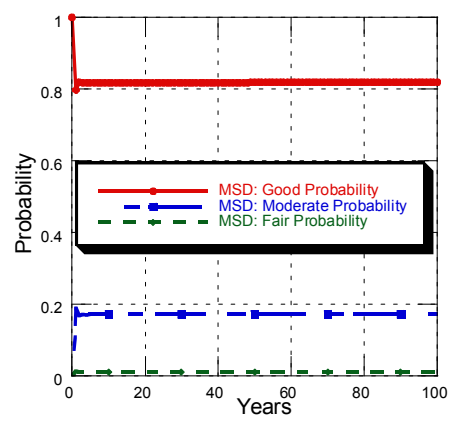

(c) MSD Deck

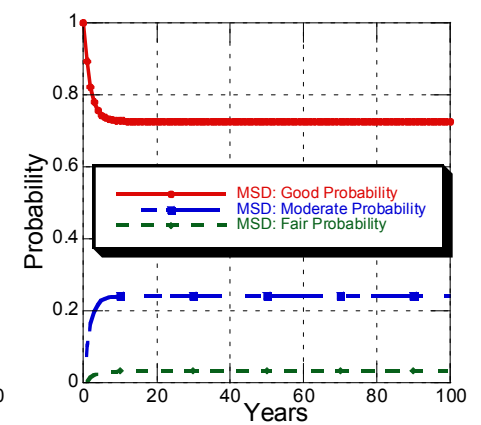

(b) MSD beam

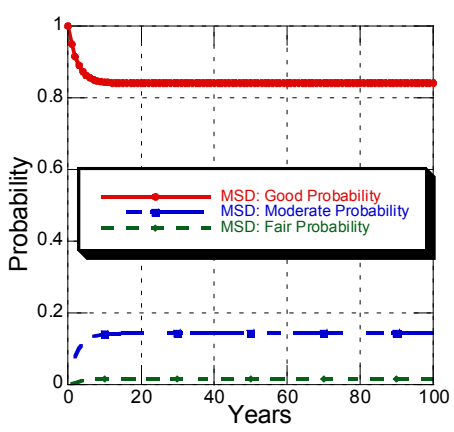

(d) MSD Bridge

Fig. 3. MSD Bridge and it's components based on model

The output of MSD model for each bridge component was used as data for making multiple linear regression for predicting the overall bridge condition. The bridge regression equation can be seen on equation $19-21$.

Probability of good: $Y=0.4003+0.4357 A+0.2458 B-0.0818 D ; R^{2}=0.9902$

Probability of moderate: $Y=0.0000-0.1766 A+0.7174 B-0.0797 D ; R^{2}=0.8163$

Probability of fail: $Y=0.0000+0.4775 A+0.0390 B-0.2880 D ; R^{2}=0.3568$

For validating the MSD model, the model should be run through data testing. The data testing employed BMS observation data from 2015 to 2016. The data were also calculated using the regression equations and the values were compared. The value obtained from MSD and regression is presented in Fig 4. As the Figure indicates, the two values has similar trends and values, although the still contain errors.

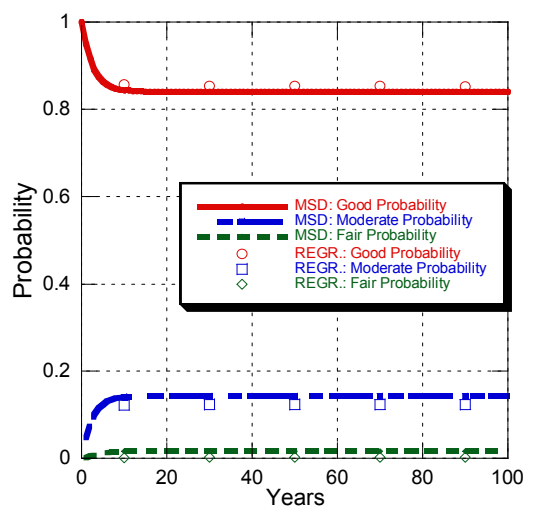

Fig. 4. Comparison of MSD and regression bridge and the component probability prediction 
To observe the bridge condition behavior due to the change of CPT bridge components, a model scenario can be used. The applied scenario can be seen in Table 4 . The scenario was designed by changing one variable only so that the outputs can be compared and the behavior can be identified.

Table 4. The scenarios of MSD model

\begin{tabular}{|l|l|c|c|c|}
\hline No & Scenario & Code & \multicolumn{2}{|c|}{$\begin{array}{c}\text { CPT values of } \\
\text { each bridge } \\
\text { components }\end{array}$} \\
\hline \multirow{2}{*}{1} & Scenario 1 & A1B1D1 & $\mathrm{M}\left(\begin{array}{ccc}1 & 0 & 0 \\
0 & 1 & 0 \\
0 & 0 & 1\end{array}\right)$ \\
\hline \multirow{2}{*}{2} & Scenario 2 & A2B2D2 & $\mathrm{M}\left(\begin{array}{cccc}0.5 & 0.5 & 0 \\
0 & 1 & 0 \\
0 & 0 & 1\end{array}\right)$ \\
\hline
\end{tabular}

\begin{tabular}{|c|c|c|c|}
\hline No & Scenario & Code & $\begin{array}{l}\text { CPT values of each } \\
\text { bridge components }\end{array}$ \\
\hline 3 & Scenario 3 & A3B3D3 & 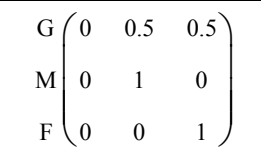 \\
\hline 4 & Scenario 4 & A4B4D4 & 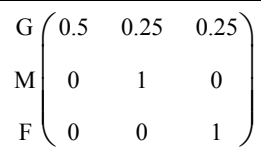 \\
\hline
\end{tabular}

In the first scenario, MSD model was given $C P T$ values $(\mathrm{G}-\mathrm{G}=1, \mathrm{M}-\mathrm{M}=1, \mathrm{~F}-\mathrm{F}=1$ and the others $=0$ ) producing identity matrix. Scenario $1^{\text {st }}$ generated bridge condition value for Good $=1$ and Moderate $=$ Fail $=0$. Thus, the behavior of bridge is only determined by the initial condition of bridge components, which are Good $=1$ and Moderate $=$ Fail $=0$ (see Fig 5a). This state was used as a reference for making the next scenario in which the CPT change was only given in a good condition (moderate and fail were fixed). Thus, it can be concluded that the bridge behavior is only affected by good condition. Therefore, the bridge behavior can be identified clearly if good is tranformed into moderate and fail in all bridge components, which were not affected by transformed the moderate or fail into other conditions.

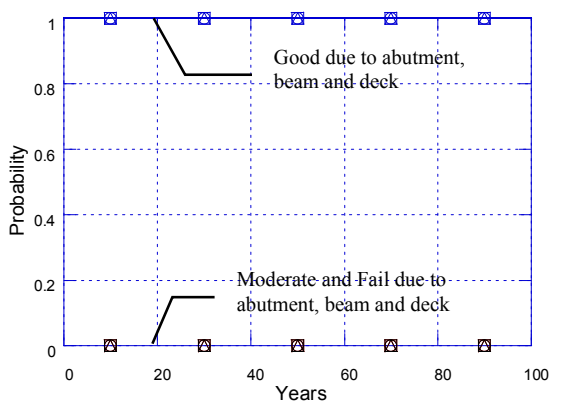

(a) Probability of bridge condition in A1B1D1

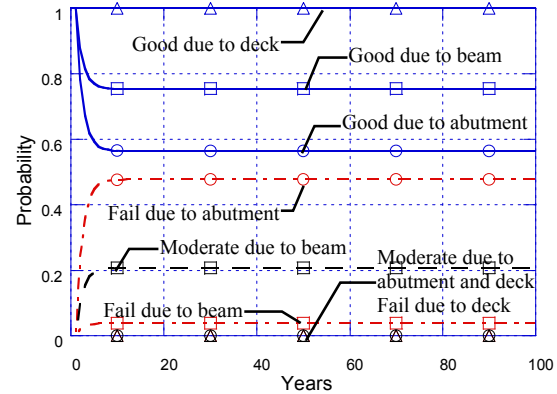

(c) Probability of bridge condition in A3B3D3

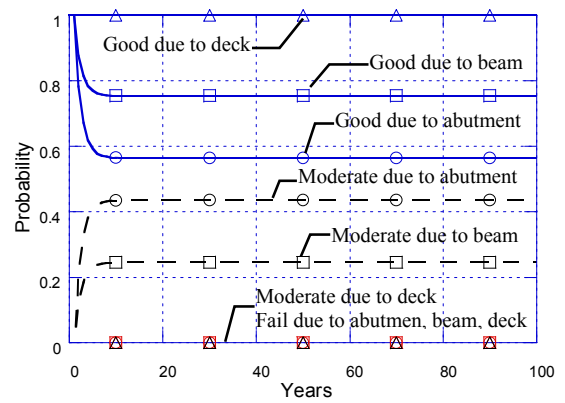

(b) Probability of bridge condition in A2B2C2

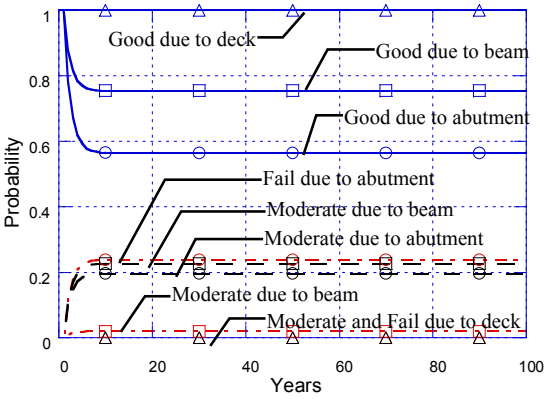

(d) Probability of bridge condition in A4B4C4

Fig.5. Probability of bridge condition in variance scenario 
The second scenario was designed to observe the bridge behaviors if all bridge components in good condition were transformed into $50 \%$ to moderate condition. The bridge behavior indicates that the good probability condition decreased from 1 to 0.56 (due to abutment), 0.75 (due to beam), and deck still had the value of 1 . The bridge moderate probability condition which previously had 0 value increased due to the transition, which is 0.44 (due to abutmen), 0.25 (due to beam), and for deck still according to the initial value. Meanwhile, the condition probability of bridge fail had the value of 0 for all bridge component effect. The result of scenario 2 can be seen in Fig $5 \mathrm{~b}$.

The next scenario was made by transforming all good condition of the bridge components to $50 \%$ to moderate and $50 \%$ to fail. The result obtained had a trend similar to scenario 2 although they had different values. There was a decrease of good from the initial condition $(=1)$ to 0.56 (due to abutment) and 0.75 (due to beam). The moderate probability changed from 0 to 0.21 (due to beam) and remained the same for abutment and deck. The fail probability of the bridge changed from 0 to 0.48 (due to abutment) and 0.04 (due to beam). The change of CPT on the deck had almost no significant effect on the bridge behavior. The graphic of MSD scenario 3 can be seen in Fig 5c.

To observe the effect of the condition value transition from good to moderate and fail simultaneously, scenario 4 was made. This scenario generated graphic presented in Fig 5d. The transition generated: (i) the decrease of good condition probability on the bridge from 1 to 0.56 (due to abutment) and 0.75 (due to beam); (ii) the increase of moderate condition probability on the bridge from 0 to 0.20 (due to abutment), 0.23 (due to beam); (iii) the increase of fail condition probability on the bridge from 0 to 0.24 (due to abutment), 0.02 (due to beam); and (iv) no effect on the bridge condition due to transition change on the deck.

Based on the result of MSD model, it can be concluded that bridge behavior is significantly influenced by the condition of bridge components, where the most influencing component is abutment, followed by beam and deck. This results align with the BMS data analyzed using the joint probability theory.

\section{Conclusion}

The proposed model, MSD, can be used to predict the condition of the bridge accurately. Simulation result shows that the condition of bridge and its components are dependent; thus, the bridge condition is strongly influenced by its components. The most dominant relationship is between the abutment and beam. MSD model can predict bridge failure in 3 state probability (good, moderate and fail).

MSD model can also be used as a reference for determining bridge condition probability, so that it can be used as a guide for the maintenance and operation of bridge. Besides predicting the probability of the bridge failure, this model can also be used as an early warning system for bridge monitoring activity.

This model, however, still has some drawbacks. The CPT calculation and multiple linear regression are still conducted manually. This is due to the limited features of Vensim PLE version used. This model also requires lengthy calculations if more scenarios are given. This is because CPT calculation is still done manually. Therefore, this model needs to be developed further to address the drawbacks.

\section{Acknowledgement}


The author would like to thank the Directorate of Bridge, Directorate General of Bina Marga, the Ministry of Public Works and Housing for providing data, manuals, and other needed information for this study.

\section{References}

1. P. Work, Book Statistical Information. Jakarta: Ministry of Public Works (2013)

2. F. U. Ashraf, P. A. Johnson, and M. Asce, J. Bridg. Eng., 2, 1-10 (2015)

3. W. Pang, D. Ph, M. Asce, and K. Dey, J. Infrastruct. Syst., 19, 326-334 (2013)

4. F. N. Catbas, M. Susoy, and D. M. Frangopol, Eng. Struct., 30, 9, 2347-2359 (2008)

5. S. Ranjith, S. Setunge, R. Gravina, and S. Venkatesan, J. Perform. Constr. Facil., 27, 319-325 (2013)

6. J. W. Soetjipto, T. J. W. Adi, and N. Anwar, Int. J. Eng. Technol. Innov., 6, 4 (2016)

7. P. Work, Bridge Inspection Guide. Jakarta: Public Work (1993)

8. S. Hasan, S. Setunge, D. W. Law, and Y. Koay, Int. J. Eng and Tech., 7, 1, 40-44 (2015)

9. G. Bu, J. Lee, H. Guan, M. Blumenstein, and Y. Loo, J. Perform. Constr. Facil., 28, 330-340 (2014)

10. Y. Huang, J. Perform. Constr. Facil., 24, 597-602 (2010)

11. K. Kwon and D. M. Frangopol, Probabilistic Eng. Mech., 26, 3, 471-480 (2011)

12. A. Agresti, An Introduction to Categorical Data Analysis, London, UK: A John Wiley \& Sons, Inc. (2007)

13. S. Leu and T. J. W Adi, Eng. Appl. Artif. Intell., 24, 4, 658-665 (2011) 